\title{
Toxicidade Aguda em Ratos Wistar Tratados com o Extrato Etanólico de Dioclea grandiflora Mart. Ex Benth (Fabaceae) (EEDg) Acute Toxicity of Dioclea grandiflora Mart. Ex Benth (Fabaceae) Ethanolic Extract in Wistar Rats
}

\author{
JOSUÉ DO AMARAL RAMALHO ${ }^{3}$ \\ IVANA FERREIRA GORGONIO' \\ ANDRESSA BRITO LIRA ${ }^{1}$ \\ MATEUS FEITOSAALVES ${ }^{2}$ \\ LUCIANA DA SILVANUNES RAMALHO ${ }^{3}$ \\ RICARDO BARROS CARDOSO ${ }^{3}$ \\ GUILHERME EDUARDO NUNES DIAS ${ }^{3}$ \\ EDLA JULINDA RIBEIRO COUTINHO ESPINOLA GUEDES ${ }^{3}$ \\ KARDILÂNDIA MENDES OLIVEIRA ${ }^{3}$ \\ REINALDO NÓBREGA DE ALMEIDA ${ }^{4}$ \\ MARGARETH DE FÁTIMA FORMIGA MELO DINIZ ${ }^{5}$ \\ ISAC ALMEIDA DE MEDEIROS ${ }^{5}$
}

RESUMO

Introdução: A Dioclea grandiflora, conhecido como Mucunã de caroço, atua sobre o Sistema Nervoso Central, doenças da próstata e pedras nos rins. Objetivo: Realizar estudo toxicológico não clínico agudo, em ratos, com base na Instrução Normativa no4, de 18 de junho de 2014 da Agência Nacional de Vigilância Sanitária (ANVISA). Material e Métodos: Foram utilizados ratos Wistar, ambos os sexos, dose 2000 $\mathrm{mg} / \mathrm{kg}$, via oral, do extrato etanólico bruto de Dioclea grandiflora administrado a um grupo tratado e um grupo controle (veículo). Após a administração, os parâmetros de comportamento foi observado por $30,60,90,120,180$ e 240 minutos, consumo de ração e água, parâmetros hematológicos e bioquímicos. O número de sobreviventes contabilizados para determinar a DL50. Resultados: Houve aumento estatisticamente significativo no consumo de água (Controle: 160,4 $\pm 5,85$; Tratado: $201,3 \pm 8,55$ ) e ração das fêmeas (Controle: 95,98 $\pm 3,02$; Tratado: $113,1 \pm 2,42$ ) e aumento estatisticamente

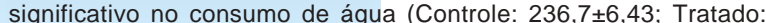
$267,5 \pm 8,72$ ) e ração dos machos (Controle: 152,4 $\pm 2,51$; Tratado: $177,64,15)$. Aumento estatisticamente significativo na albumina dos machos (Controle: $3,2 \pm 0,08$; Tratado: $3,6 \pm 0,08$ ), nas fêmeas reduziu estatisticamente significativo a fosfatase alcalina (Controle: 198,5 $\pm 18,81$; Tratado: $99,97 \pm 16,02$ ) , proteína total (Controle: 7,85 $\pm 0,09$; Tratado: $6,85 \pm 0,24$ ) e globulinas (Controle: $4,28 \pm 0,14$; Tratado: $3,27 \pm 0,27)$. Diminuiu estatisticamente significativo o número de hemácias nas fêmeas (Controle: 10,18 $\pm 0,28$; Tratado: 9,62 $\pm 0,18$ ). Conclusão: De acordo com os resultados a DL50 foi superior à dose testada, porém são necessários estudos toxicológicos de longa duração para atestar a segurança de seu uso.

\section{DESCRITORES}

Sistema Nervoso Central. Toxicidade Aguda. Ratos Wistar.

\begin{abstract}
Introduction: Dioclea grandiflora, known as Mucunã de caroço, acts on the central nervous system, and against prostate disease and kidney stones. Objective: To perform a nonclinical acute toxicology study in rats following the Normative Instruction \#4 as of June $18^{\text {th }} 2014$ of the National Health Surveillance Agency (ANVISA). Material and Methods: Wistar rats of both sexes were used in the study. A dose of $2000 \mathrm{mg} /$ $\mathrm{kg}$ of Dioclea grandiflora ethanolic extract was administered orally to the test group. A control group using only the vehicle was also included. Then behavioral parameters were monitored for $30,60,90,120,180$, and 240 minutes after feed and water intake, along with hematological and biochemical parameters. The number of survivors was recorded to determine the LD . Results: There was a statistically significant increase in water (Control: $160.4 \pm 5.85$; Treated: $201.3 \pm 8.55$ ), and feed intake (Control: $95.98 \pm 3.02$; Treated: $113.1 \pm 2.42$ ) for female rats; and a statistically significant increase in water (Control: $236.7 \pm$ 6.43; Treated: $267.5 \pm 8.72$ ) and feed intake (Control: $152.4 \pm 2.51$; Treated: $177.6 \pm 4.15$ ) for males. A statistically significant increase in albumin levels was observed for males (Control: $3.2 \pm 0.08$; Treated: $3.6 \pm 0.08$ ), and a decrease in alkaline phosphatase (Control: $198.5 \pm$ 18.81; Treated: $99.97 \pm 16.02$ ), total protein (Control: $7.85 \pm 0.09$; Treated: $6.85 \pm 0.24$ ) and globulin (Control: $4.28 \pm 0.14$; Treated: 3.27 \pm 0.27 ) was found for females. Also, in females the number of red blood cells was found to be significantly reduced (Control: $10.18 \pm$ 0.28 ; Treated: $9.62 \pm 0.18$ ). Conclusion: According to the results, the $\mathrm{LD}_{50}$ value found was higher than that of the tested dose. However long-term toxicology studies are needed to further prove the safety of the extract.
\end{abstract}

\section{DESCRIPTORS}

Central Nervous System. Acute Toxicity. Wistar Rats.

1 Aluno(a) de Iniciação Científica ( PIVIC/UFPB ),

2 Doutorando do Programa de Pós-Graduação em Produtos Naturais Sintéticos Bioativos - CCS - UFPB,

3 Doutorando do Programa de Desenvolvimento e Inovação Tecnológica em Medicamentos - UFPB/UFRPE/UFC/UFRN,

4 Professor(a) do Departamento de Fisiologia e Patologia - CCS - UFPB,

5 Professor(a) do Departamento de Ciências Farmacêuticas - CCS - UFPB. 
$\mathrm{A}$ natureza tem servido como fonte de medicamentos por milênios, sendo muitas drogas desenvolvidas a partir de fontes vegetais $^{1}$. Em virtude dos seus efeitos terapêuticos, os compostos vegetais são comumente utilizados pela população ${ }^{2}$. No entanto, como diversas espécies vegetais utilizadas na medicina empírica não possuem seu efeito farmacológico elucidado, o conhecimento popular destes produtos naturais tornou-se a base e o direcionamento para muitos estudos ${ }^{3}$.

No mundo, estima-se que apenas $15 \%$ das 300 mil espécies de plantas tenham sido submetidas a algum estudo científico para avaliar seu potencial na preparação de novos produtos. Além disso, a utilização de técnicas modernas de isolamento e identificação de compostos químicos obtidos de fontes naturais tem propiciado um aumento na descoberta de novas estruturas químicas ${ }^{4}$.

Entretanto, várias plantas medicinais da flora nativa são consumidas com pouca ou nenhuma comprovação de suas propriedades farmacológicas e tóxicas, podendo assim acarretar um sério problema de saúde pública. É importante ressaltar que efeitos adversos, adulteração do produto, toxicidade e interações medicamentosas são possíveis de ser verificados tanto com medicamentos alopáticos convencionais quanto com os fitoterápicos. Do ponto de vista científico, pesquisas mostraram que muitas delas possuem substâncias potencialmente agressivas e, por esta razão, devem ser utilizadas com cuidado, respeitando seus riscos toxicológicos ${ }^{5}$.

A Toxicologia tem como objeto de estudo a observação destes efeitos prejudiciais, conhecidos como efeitos tóxicos, qualquer que seja a substância química causadora e trabalha dentro de um princípio que consiste em conhecer o risco da exposição humana frente a diversos produtos para ser possível estabelecer as condições seguras de exposição a estes agentes ${ }^{6}$. As fases de um estudo toxicológico não-clínico estão bem definidas atualmente. No Brasil, uma das normas que regulamentam este estudo é a Resolução RDC $n^{\circ}$ 26, de 13 de maio de 2014, que dispõe sobre o registro de medicamentos fitoterápicos e a Instrução Normativa $\mathrm{N}^{\circ} 04$ de 18 de junho de 2014 determina que os ensaios de toxicologia não-clínica deverão utilizar como parâmetros mínimos o Guia para a condução de estudos não-clínicos de toxicologia e segurança farmacológica necessária ao desenvolvimento de medicamentos (ANVISA).

A Dioclea grandiflora Mart. Ex . Benth
(Fabaceae), popularmente conhecido como "mucuna ", "mucuna-de-caroço " e "olho-de-boi", é uma planta trepadeira que cresce na caatinga e cerrado, regiões do Nordeste do Brasil. De acordo com a tradição popular, a casca das sementes desta planta e das raízes têm sido amplamente utilizados para tratar doenças da próstata e pedras nos rins ${ }^{7}$. Estudos fitoquímicos mostrou a presença de várias substâncias na Dioclea grandiflora, tais como o paraibanol, agrandol e diosalol (8), dioclein, dioflorin, diidroflavonol, dioclenol ${ }^{9-10}$, isolado a partir do clorofórmio (CHCI3) porção solúvel do extrato de casca da raiz desta planta. Investigações anteriores evidenciaram uma atividade significativa no SNC do extrato etanólico obtido a partir da casca da raiz seca ${ }^{11}$, e do extrato hidroalcoólico a partir das sementes de Dioclea grandiflora ${ }^{12}$. O seu principal constituinte, diocleína, tem um efeito analgésico significativo em roedores $^{13}$, e um efeito vasorrelaxante no endotélio da aorta de rato $^{14}$. A triagem farmacológica também revelou a atividade antinoceptiva de dioclenol e dioflorin em camundongos ${ }^{15}$. Um estudo foi realizado com uma outra parte da planta, as vagens, e relatou atividade antinoceptiva eficaz em camundongos ${ }^{16}$.

$O$ teste de toxicidade aguda, por via intraperitoneal, na dose de $250 \mathrm{mg} / \mathrm{kg}$ do extrato etanólico de Dioclea grandiflora não provocou a morte de nenhum dos animais tratados, enquanto que as doses de 500, 1000, e $2000 \mathrm{mg} / \mathrm{kg}$, matou $10 \%$, $90 \%$ e $100 \%$ dos animais tratados, respectivamente. As mortes ocorreram dentro de um período de observação de 14 dias. Portanto, estes dados indicam que a DL50 para este extrato é $753 \mathrm{mg} / \mathrm{kg}^{17}$.

O objetivo do presente estudo foi avaliar a toxicidade não-clínica aguda do Extrato Etanólico de Dioclea grandiflora Mart. Ex Benth (Fabaceae) (EEDg), por via oral, segundo a Instrução Normativa N ${ }^{\circ} 04$ de 18 de Junho de 2014 da ANVISA.

\section{MATERIAL E MÉTODOS}

\section{Preparação do extrato etanólico de Dioclea grandiflora Mart}

As cascas das raízes foram submetidas a um processo de extração utilizando o aparelho de Soxhlet, por um período de 24 horas, sendo o solvente extrator uma solução de etanol a $95 \%$ e concentrados em evaporador rotatório em uma temperatura de $60^{\circ} \mathrm{C}$. 
Animais

Foram utilizados ratos Wistar (Ratus novergicus), albinos, adultos, machos e fêmeas (nulíparas e não grávidas), pesando entre 180 e 250 gramas, fornecidos pelo biotério Prof. Thomas George do Instituto de Pesquisa em Fármacos e Medicamentos - IPeFarM da Universidade Federal da Paraíba - UFPB. Foram agrupados em gaiolas de polietileno, mantidos sob condições controladas de temperatura de $27 \pm 2^{\circ} \mathrm{C}$, sem uso de qualquer medicamento, tendo livre acesso à comida (tipo pellets) e água potável disponível em garrafas graduadas de polietileno, com bicos em aço inox, colocadas nas grades metálicas das gaiolas na sua parte superior. As atividades de pesquisa foram desenvolvidas no Laboratório de Ensaios Toxicológicos (LABETOX) - IPeFarM da Universidade Federal da Paraíba-UFPB.

\section{Ensaio toxicológico agudo}

No estudo de toxicidade aguda, foram utilizados ratos Wistar, sendo 12 machos e 12 fêmeas, sendo 6 animais por caixa, os animais receberam a dose de 2000 $\mathrm{mg} / \mathrm{Kg}$ de peso corporal por via oral do EEDg. Após administração, foram observados os efeitos gerais apresentados pelos animais experimentais nos intervalos: 30, 60, 90, 120, 180 e 240 minutos no primeiro dia e uma vez ao dia, sempre no mesmo horário, nos 13 dias seguintes, com o objetivo de mapear possíveis alterações comportamentais, sugestivas de atividade sobre o Sistema Nervoso Central (SNC) ou no Sistema Nervoso Autônomo (SNA), utilizando-se protocolo experimental, elaborado pelo Setor de Psicofarmacologia 18. Um grupo também com 12 animais (6 machos e 6 fêmeas) tratado com o veículo de diluição do extrato, permaneceu como grupo controle.

Diariamente, foram observados o consumo de água, a ingestão de alimentos e a evolução ponderal semanal. Após o $14^{\circ} \mathrm{dia}$, os animais sobreviventes e os animais do grupo controle, foram eutanasiados, sendo coletada amostra do sangue, para análise laboratorial dos parâmetros bioquímicos e hematológicos.

\section{Análise laboratorial do sangue}

O sangue foi coletado em tubos com anticoagulante ácido etilenodiamino tetracético (EDTA) para determinação dos parâmetros hematológicos e em tubos com gel separador - Microtainer Becton Dickson ${ }^{\circledR}$ - centrifugados por 5 minutos a $3.500 \mathrm{rpm}$, para obtenção do soro para determinação dos parâmetros bioquímicos.

\section{Parâmetros hematológicos}

As análises hematológicas constaram do estudo da série vermelha (eritrograma), branca (leucograma) e contagem de plaquetas. No eritrograma foi realizada a contagem de hemácias, determinação do hematócrito, da hemoglobina, volume corpuscular médio (VCM), da hemoglobina corpuscular média (HCM), e da concentração da hemoglobina corpuscular média (CHCM). No leucograma a contagem global dos leucócitos e contagem da diferenciação celular.

\section{Parâmetros bioquímicos}

As análises bioquímicas realizadas em amostras de soro das dosagens de glicose, uréia, colesterol total, triglicerídios, ácido úrico, creatinina, transaminases: Aspartato Amino Transferase (AST) e Alanina Amino Transferase (ALT), Gama Glutil Transferase (GGT), fosfatase alcalina e proteínas totais e frações realizadas no analisador bioquímico automatizado COBAS MIRA PLUS $^{\circledR}$ - ROCHE. O sódio, potássio, cálcio, magnésio e cloreto determinados pelo analisador de íons seletivos Electrolyte Analyzer AVLAB®.

\section{Análise estatística}

Para análise estatística dos resultados, foi utilizado o Teste " $t$ " de Student não pareado, utilizando o Software Graph Pad Prism 6.0, sendo os resultados considerados significativos quando apresentaram valores de $\mathrm{p}<0,05$.

\section{RESULTADOS}

\section{Consumo de água e ração:}

Os resultados, mostrados na Tabela 1 , demonstram aumento estatisticamente significativo no consumo de água e ração de machos e fêmeas tratados com a dose de 2000mg/Kg do Extrato Etanólico de Dioclea grandiflora Mart. Ex. Benth ( EEDg), durante 14 dias. 


Tabela 1. Consumo de água e ração de ratos, machos e
fêmeas, tratados com a dose de $2000 \mathrm{mg} / \mathrm{kg}$ do Extrato
Etanólico de Dioclea grandiflora Mart. Ex. Benth durante o
ensaio de toxicidade aguda. Os valores estão expressos
em média \pm e.p.m. (n=6). Teste "t" de Student." $\mathrm{p}<0.05$.
$\begin{array}{ccc}\text { Grupo } & \text { Consumo de Água } \\ \text { ( } \mathrm{mL} \text { ) } & \text { Consumo de Ração } \\ \text { (q) }\end{array}$

\section{Machos}

\begin{tabular}{lll} 
Controle & $236.7 \pm 6.43$ & $152.4 \pm 2.51$ \\
Tratado & $267.5 \pm 8,72^{*}$ & $177,6 \pm 4.15^{\circ}$ \\
Grupo & Consumo de Áqua & Consumo de Ração \\
Controle & $160.4 \pm 5.85$ & Fêmeas \\
Tratado & $201.3 \pm 8.55^{*}$ & $95.98 \pm 3.02$ \\
\hline
\end{tabular}

Os resultados na tabela 2 demonstram que houve diminuição estatisticamente significativa na dosagem de fosfatase alcalina, proteínas totais e globulina das fêmeas tratados com a dose de 2000mg/
Kg e aumento estatisticamente significativo na dosagem de albumina dos machos tratados com a dose de 2000mg/ Kg do Extrato Etanólico de Dioclea grandiflora Mart. Ex. Benth (EEDg), durante 14 dias.

\begin{tabular}{|c|c|c|c|c|c|c|c|c|c|}
\hline Grupos & $\begin{array}{l}\text { Glicose } \\
\text { (mgldl) }\end{array}$ & $\begin{array}{c}\text { Uréia } \\
\text { (mgidlt) }\end{array}$ & $\begin{array}{c}\text { Creatinina } \\
\text { (mg/dl) }\end{array}$ & $\begin{array}{c}\text { Colesterol } \\
\text { (mg/dL) }\end{array}$ & $\begin{array}{l}\text { Triglicerideos } \\
\text { (mg/dL) }\end{array}$ & $\begin{array}{l}\text { Acido } \\
\text { Urico } \\
\text { (mqidL) }\end{array}$ & AST (UII) & $\begin{array}{l}\text { ALT } \\
\text { (UNI) }\end{array}$ & $\begin{array}{c}\text { Fosiatase } \\
\text { Alcalina } \\
\text { (UII) }\end{array}$ \\
\hline & \multicolumn{9}{|c|}{ Machos } \\
\hline Controle & $\begin{array}{c}109,8 \pm \\
5.23\end{array}$ & $\begin{array}{c}43,40 \pm \\
3,36\end{array}$ & $0,56+0,03$ & $\begin{array}{c}55,80 \pm \\
3.51\end{array}$ & $138,6 \pm 13,94$ & $\begin{array}{l}1,04 \pm \\
0.07\end{array}$ & $\begin{array}{c}301,8 \pm \\
20,14\end{array}$ & $\begin{array}{c}93,00 \pm \\
4,30\end{array}$ & $\begin{array}{l}212,8 \pm \\
17,74\end{array}$ \\
\hline \multirow[t]{2}{*}{ Tratado } & $\begin{array}{r}124,7 \pm \\
12.81\end{array}$ & $\begin{array}{c}44,00 \pm \\
1.0\end{array}$ & $0,57 \pm 0,03$ & $\begin{array}{c}69,00 \pm \\
5,69\end{array}$ & $180,00 \pm 19,00$ & $\begin{array}{l}1,07 \pm \\
0.37\end{array}$ & $\begin{array}{c}157,00 t \\
15,00\end{array}$ & $\begin{array}{l}75,67 \pm \\
13.57\end{array}$ & $\begin{array}{l}169,3 \pm \\
29,01\end{array}$ \\
\hline & \multicolumn{9}{|c|}{ Fèmeas } \\
\hline Controle & $\begin{array}{c}118,7 \pm \\
6,24\end{array}$ & $\begin{array}{l}51,5 \pm \\
3.55\end{array}$ & $0,62+0,02$ & $\begin{array}{c}52,17 \pm \\
3,8\end{array}$ & $112,00 \pm 4,0$ & $\begin{array}{l}1,27 \pm \\
0.22\end{array}$ & $\begin{array}{c}268,2 \pm \\
41,21\end{array}$ & $\begin{array}{l}77,83 \pm \\
8,82\end{array}$ & $\begin{array}{l}198,5 \pm \\
18,81\end{array}$ \\
\hline Tratado & $\begin{array}{c}121,2 \pm \\
8,05\end{array}$ & $\begin{array}{c}47,50 \pm \\
2.51\end{array}$ & $0,57 \pm 0,06$ & $\begin{array}{c}63,33 \pm \\
4,7\end{array}$ & $96,83 \pm 15,2$ & $\begin{array}{l}1,28 \pm \\
0.25\end{array}$ & $\begin{array}{c}183,00 \pm \\
48,18\end{array}$ & $\begin{array}{c}74,50 \pm \\
7,20\end{array}$ & $\begin{array}{l}99,97 \pm \\
16.02^{*}\end{array}$ \\
\hline
\end{tabular}




\begin{tabular}{|c|c|c|c|c|c|c|c|}
\hline Grupos & $\begin{array}{l}\mathrm{Ca}^{+2} \\
(\mathrm{~g} / \mathrm{dL})\end{array}$ & $\begin{array}{l}\text { Magnésio } \\
(\mathrm{g} / \mathrm{dL})\end{array}$ & $\begin{array}{l}\text { LDH } \\
\text { (U/I) }\end{array}$ & $\begin{array}{l}\text { Amilase } \\
\text { (U/dL) }\end{array}$ & $\begin{array}{c}\text { Proteinas } \\
\text { totais } \\
\text { (a/dL) }\end{array}$ & $\begin{array}{l}\text { Albumina } \\
\text { (g/dL) }\end{array}$ & $\begin{array}{l}\text { Globulina } \\
\text { (g/dL) }\end{array}$ \\
\hline \multicolumn{8}{|c|}{ Machos } \\
\hline Controle & $\begin{array}{c}11,26 \pm \\
0,7\end{array}$ & $1,96 \pm 0,07$ & $\begin{array}{l}3617 \pm \\
344.8\end{array}$ & $653,2 \pm 14,92$ & $7,22+0,13$ & $3,2+0,08$ & $4,02+0,09$ \\
\hline Tratado & $\begin{array}{c}12,30 \pm \\
0,8\end{array}$ & $1,99 \pm 0,09$ & $\begin{array}{l}2815 \pm \\
460.5\end{array}$ & $695,7 \pm 9,82$ & $7,63 \pm 0,59$ & $3,6 \pm 0,08^{*}$ & $4,07 \pm 0,05$ \\
\hline \multicolumn{8}{|c|}{ Fèmeas } \\
\hline Controle & $\begin{array}{c}12,77 \pm \\
0,32\end{array}$ & $1,93 \pm 0,10$ & $\begin{array}{l}3139 \pm \\
555.5\end{array}$ & $396,2 \pm 9,78$ & $7,85 \pm 0,09$ & $3,57 \pm 0,07$ & $4,28 \pm 0,14$ \\
\hline Tratado & $\begin{array}{c}13,67 \pm \\
0,42\end{array}$ & $2,04 \pm 0,15$ & $\begin{array}{l}2182 \pm \\
419.1\end{array}$ & $371,8+25,04$ & $6,85 \pm 0,24^{*}$ & $3,75 \pm 0,09$ & $3,27 \pm 0,27^{*}$ \\
\hline
\end{tabular}

Os resultados na tabela 3 , demonstram que houve diminuição estatisticamente significativo nas hemácias das fêmeas tratados com a dose de 2000mg/
$\mathrm{Kg}$ com a dose de 2000mg/Kg do Extrato Etanólico de Dioclea grandiflora Mart. Ex. Benth (EEDg), durante 14 dias.

「abela 3. Parâmetros hematológicos obtidos do soro de ratos tratados com a dose de $2000 \mathrm{mg} / \mathrm{kg}$ do Extrato Etanólico de Dioclea grandifiora Mart. Ex. Benth (Fabaceae) (EEDg) durante o ensaio de toxicidade ıquda. Os valores estão expressos em média \pm e.p.m. $(n=6)$. Teste " 4 " de Student." $p<0,05$.

\begin{tabular}{|c|c|c|c|c|c|c|}
\hline & $\begin{array}{l}\text { Hemácias } \\
\left(10 \% / \mathrm{mm}^{3}\right)\end{array}$ & $\begin{array}{l}\text { Hemoglobina } \\
\text { (a/dl) }\end{array}$ & $\begin{array}{l}\text { Hematócri } \\
\text { to }(\%)\end{array}$ & $\operatorname{VCM}\left(\mu^{3}\right)$ & $\mathrm{HCM}(\mu \mu \mathrm{g})$ & $\mathrm{CHCM}(\%)$ \\
\hline \multicolumn{7}{|c|}{ Machos } \\
\hline Controle & $10.21 \pm 0.23$ & $16.5 \pm 0.29$ & $47,9 \pm 1,19$ & $47,00 \pm 0.45$ & $16.18 \pm 0.21$ & $34.48 \pm 0.31$ \\
\hline Tratado & $10,12+0,43$ & $16,6 \pm 0,27$ & $48,3+2,49$ & $48,00 \pm 0,58$ & $16,50 \pm 0,50$ & $34,53 \pm 1,35$ \\
\hline \multicolumn{7}{|c|}{ Fềmeas } \\
\hline Controle & $10.18+0.28$ & $15.98 \pm 0.39$ & $47,5 \pm 1,63$ & $46,6 \pm 0.74$ & $15.68 \pm 0.19$ & $33,68 \pm 0.47$ \\
\hline \multirow[t]{2}{*}{ Tratado } & $9.62 \pm 0,18^{\circ}$ & $15,46 \pm 0,28$ & $44,3 \pm 0,86$ & $46,0 \pm 0,44$ & $16,08 \pm 0,16$ & $34,9 \pm 0,37$ \\
\hline & $\begin{array}{c}\text { Leucócitos } \\
(10 / \mathrm{mm})\end{array}$ & $\begin{array}{c}\text { Neutrófilo } \\
(\%)\end{array}$ & $\begin{array}{c}\text { Eosinófilo } \\
(\%)\end{array}$ & $\begin{array}{l}\text { Linfócito } \\
\text { (\%) }\end{array}$ & $\begin{array}{c}\text { Monócito } \\
(\%)\end{array}$ & $\begin{array}{c}\text { Plaquetas } \\
(10 / \mathrm{mm})\end{array}$ \\
\hline \multicolumn{7}{|c|}{ Machos } \\
\hline Controle & $7.62+0.53$ & $28.6+2.42$ & $0.8 \pm 0.2$ & $60.60 \pm 3.12$ & $9.8 \pm 1.2$ & $631 \pm 38.42$ \\
\hline \multirow{2}{*}{\multicolumn{7}{|c|}{ Fèmeas }} \\
\hline & & & & & & \\
\hline Controle & $6.26 \pm 0.7$ & $25.4 \pm 0.68$ & $1.8+0.49$ & $66.2+1.34$ & $6.6 \pm 0.68$ & $605.6 \pm 66.56$ \\
\hline Tratado & $6.05 \pm 0,9$ & $29.5 \pm 4.11$ & $1,0 \pm 0,40$ & $62.3 \pm 4,2$ & $7.3 \pm 1,65$ & $633,3 \pm 39,16$ \\
\hline
\end{tabular}




\section{DISCUSSÃO}

O uso de plantas é uma prática prevalente na população, principalmente onde as condições sociais e econômicas são mais precárias. Considerando a importância destes aspectos é que foi realizado um estudo que objetivou a investigação da toxicidade não clínica aguda do Extrato Etanólico de Dioclea grandiflora Mart. Ex. Benth em ratos submetidos à dose de $2000 \mathrm{mg} / \mathrm{kg}$, via oral.

A triagem farmacológica ${ }^{18}$ apresenta uma metodologia para screening farmacológico de extratos, substâncias, dentre outros produtos de origem vegetais com possíveis atividades no Sistema Nervoso Central, avaliando-se através de um elenco de comportamentos pré-estabelecidos, possíveis de serem observados em qualquer Laboratório de Farmacologia Experimental, que correspondem a atividades estimulantes e depressoras sobre o SNC e atividades sobre o Sistema Nervoso Autônomo ${ }^{18}$. Na observação da triagem farmacológica ${ }^{18}$ não foi evidenciado nenhuma alteração em ambos os sexos no período de tempo avaliado.

A ingestão de água e de nutrientes são parâmetros importantes no estudo da segurança de um produto com fins terapêuticos, são essenciais para o bom funcionamento do sistema fisiológico dos animais e, consequentemente, para uma adequada resposta à droga testada, já que condições nutricionais impróprias podem acarretar deficiência do organismo ${ }^{19}$.

A fosfatase alcalina encontrada no soro é resultado da presença de diferentes isoenzimas originadas em diferentes órgãos, com predomínio das frações renais, ósseas e hepáticas. É também uma enzima presente em praticamente todos os tecidos do organismo, especialmente nas membranas das células dos túbulos renais, ossos (osteoblastos), placenta, trato intestinal e fígado. A análise desse parâmetro irá mostrar se existe alguma doença óssea, nas quais ocorre diminuição da atividade das células ósseas, bem como patologias hepáticas e desvio cardiopulmonar ${ }^{20}$.

Os perfis de hipoproteinemias resultantes da desnutrição ou da perda proteica importante apresentam redução em todas as frações, portanto, aumento e diminuição de proteínas são anormalidades laboratoriais comumente encontradas em animais. Tais alterações se devem a anormalidades no teor de albumina/globulina. A interpretação das alterações no teor de proteína depende da identificação da fração protéica do soro ou plasma (albumina, globulina e, no plasma, fibrinogênio). Aumento ou diminuição na concentração de albumina ou globulina nem sempre provoca alteração detectável do conteúdo da proteína total. Portanto, na interpretação dessas alterações devem-se avaliar os teores de albumina e de globulina, além da concentração de proteína total. A globulina na forma de haptoglobina tem a função de se combinar com a hemoglobina liberada pela lise dos eritrócitos a fim de preservar as reservas de ferro corporal e de proteínas. Concentrações baixas de haptoglobina podem acompanhar as hepatopatias quando a capacidade sintética do fígado encontra-se comprometida $^{21}$.

Os aumentos nas concentrações séricas de albumina são pouco frequentes, embora acorram em casos de desidratação na medida em que a fase líquida do plasma sofre retração, após a reidratação, a concentração de albumina deve voltar aos valores de referência normais ${ }^{21}$.

Hemácias são unidades morfológicas da série vermelha do sangue, também designadas por eritrócitos ou glóbulos vermelhos, que estão presentes no sangue em número de cerca de 4,5 a 6,5 x $10^{6} / \mathrm{mm}^{3}$, em condições normais. São constituídas basicamente por globulina e hemoglobina (composta de 4 moléculas proteicas de estrutura terciária e 4 grupamentos heme) que contém o ferro (cada íon ferro é capaz de se ligar frouxamente a dois átomos de oxigênio, um para cada molécula de hemoglobina), e a sua função é transportar o oxigênio (principalmente) e o gás carbônico (em menor quantidade) aos tecidos. E apresenta o seu número reduzido em alguns tipos de anemias $^{22}$.

Todos os valores estão dentro da normalidade de acordo com parâmetros hematológicos e bioquímicos de Ratos Wistar do Biotério Professor Thomas George $-\mathrm{UFPB}^{22}$.

Conforme protocolos internacionais, o estudo de toxicidade em doses repetidas deverá ser conduzido a partir dos resultados dos testes de toxicidade aguda. Esse teste visa identificar o espectro de toxicidade cumulativa do produto, podendo ser descrito 
primeiramente, pelos órgãos alvo afetados, reversibilidade das lesões, avaliação dos parâmetros clínicos, além de ser fonte de informação das doses a serem estudadas nos testes de toxicidade crônica onde o período de administração é de 90 dias.

As observações clínicas diárias dos animais nos testes de toxicidade aguda são também importantes para o direcionamento da escolha das doses utilizadas nos estudos de toxicidade em doses repetidas, visto que a seleção dessas doses é um ponto crítico.

Essas devem ser maiores que a dose sugerida para uso em humanos, em média 10 vezes $^{24}$, assim como aquelas avaliadas em animais, onde intervalos de dez a vinte e cinco vezes entre as mesmas são considerados adequados, sendo que a maior dose deve ser escolhida com o objetivo de induzir toxicidade mas não a morte ou sofrimento severo dos animais e a menor dose não deverá apresentar efeitos adversos ${ }^{23}$.

\section{CONCLUSÃO}

Diante dos resultados desse estudo, podemos concluir que a DL50 é superior à dose testada de $2000 \mathrm{mg} / \mathrm{Kg}$ do Extrato Etanólico de Dioclea grandiflora, apresenta uma excelente tolerância dando suporte para estudos de longa duração apresentando uma baixa toxicidade na dose avaliada.

\section{REFERÊNCIAS}

1. Cragg GM, Newman DJ. Natural products: A continuing source of novel drug leads. Biochimica et Biophysica Acta (BBA). 2013; 1830 (6): 3670-3695.

2. Vido DLR. Comparação da composição química e das atividades biológicas dos óleos essenciais de folhas de população de Hedyosmum brasiliense Mart. Ex Miq proveniente da Serra do Mar e da Serra da Mantiqueira (Mata Atlântica) [Dissertação]. São Paulo: Instituto de Botânica da Secretaria do Meio Ambiente; 2009.

3. Montes LV, Broseghini LP, Andreatta FS, Sant'anna MÊS, Neves VM, Silva AG. Evidências para o uso da óleoresina de copaíba na cicatrização de ferida [Revisão Sistemática]. Natureza on line. 2009; 7: 61-67.

4. Brandão MGL, Souza JP, Grael CFF, Scalon V, Santos ACP, Salimenha MF, Monte-Mor RLM. Biodiversidade, uso tradicional de plantas medicinais e produção de fitoterápicos em Minas Gerais. In: Anais do XIV Seminário sobre a Economia mineira, 2010; Minas Gerais.

5. Veiga Junior VF, Pinto AC, Maciel MAM. Plantas medicinais: cura segura. Química Nova. 2005; 28(3): 519-528.

6. Barros SBM, Davino SC. Avaliação da Toxicidade. In: S. Oga. Fundamentos de Toxicologia. 2. ed. São Paulo: Atheneu; 2003.

7. Lima AD. Plantas da Caatinga. 1 ed. Rio de Janeiro: Academia Brasileira de Ciências; 1989.

8. Jenkins T, Bhattacharyya J, Teng Q, Agra MF, Almeida $\mathrm{RN}$. Flavonoids from the root-bark of Dioclea grandiflora. Phytochemistry. 1999; 52: 723-730.

9. Bhattacharyya J, Batista JS, Almeida RN. Dioclein, a lavanone from the roots of Dioclea grandiflora. Phytochemistry, 1995; 38: 277-278.

10. Bhattacharyya J, Majetich G, Spearing P, AlmeidaRN. Dioclenol, a minor flavanonol from the root-bark of Dioclea grandiflora. Phytochemistry. 1997; 46: 385387.
11. Bhattacharyya J, Majetich G, Jenkins TM, Almeida RN. Dioflorin, a minor flavonoid from Dioclea grandiflora. $J$ Nat Prod. 1998; 61: 413-414.

12. Batista JS, Almeida RN, Bhattacharyya J. Analgesic effect of Dioclea grandiflora constituents in rodents. J Ethnopharmacol.1995; 45: 207-210.

13. Almeida ER, Almeida RN, Navarro DS, Bhattacharryya J, Silva BA, Birnbaun JSP. Central antinociceptive effect of a hydroalcoholic extract of Dioclea grandiflora seeds in rodents. J Ethnopharmacol. 2003; 88: 1-4.

14. Lemos VS, Freitas MR, Muller B, Lino YD, Queiroga CEG, Côrtes SF. Dioclein, a new nitric oxide- and endothelium-dependent vasodilator flavonoid. Eur $J$ Pharmacol. 1999; 386: 41-46.

15. Almeida RN, Navarro, DS, Agra MF, Almeida ER, Majetich G, Bhattacharyya J. Analgesic effect of dioclenol and dioflorin isolated from Dioclea grandiflora. Pharm Biol. 2000; 38: 394-395.

16. Sá RCS, Oliveira LEG, Nobrega FFF, Bhattacharyya J, Almeida RN. Antinociceptive and Toxicological Effects of Dioclea grandiflora Seed Pod in Mice. Journal of Biomedicine and Biotechnology. 2010; 2010: 1-6.

17. Sá RCS, Oliveira LEG, Fonseca DV, Bhattacharyya J, Salvadori MGSS, Almeida R N. Central Nervous System effects of Dioclea grandiflora pods on mice. Boletín Latinoamericano y del Caribe de Plantas Medicinales y Aromáticas. 2013; 12(5):.446-456.

18. Almeida RN, Oliveira TML. Triagem Farmacológica Comportamental. In: Almeida R N. Psicofarmacologia. Fundamentos Práticos. Rio de Janeiro: Guanabara Koogan, 2006.

19. Stevens KR, Mylecraine L. Issues in chronic toxicology. In: Hayes AW. Principles and methods of toxicology. 3 ed. New York: Raven Press; 1994.

20. Henry JB. Enzimologia Clínica. In: Robert D. Diagnósticos Clínicos e Tratamento por métodos laboratoriais. 20 ed. Barueri-SP: Manole; 2008. 
21. Castello Branco ACS, Diniz MFFM, Almeida RN, Santos HB, Oliveira KM, Ramalho JA, Dantas JG. Parâmetros bioquímicos e hematológicos de ratos wistar e camundongos swiss do biotério professor Thomas George. RBCS. 2011; 15(2): 209-214.

22. Lorenzi TF. Anemias. In: Lorenzi TF. Manual de hematologia: propedêutica e clínica. Ed. 4. Rio de Janeiro: Guanabara Koogan, 2006.

23. Eaton DL, Klaassen CD. Principles of toxicology. In Casarett \& Doulls. Toxicology: The basic science of poisons. 5 ed. New York: McGraw-Hill; 1996.

24. OECD GUID ELIN E FOR THE TESTIN G OF CHEMICALS. Adopted by the Council on 27th, July 1995.

\section{Correspondência}

Josué do Amaral Ramalho

Universidade Federal da Paraíba - UFPB

Bairro: Castelo Branco, s/n

João Pessoa - Paraíba - Brasil

CEP: 58051-970

E-mail: josueramalho@yahoo.com.br 